\title{
Investigating the antecedents of innovative behaviors in the hotel industry of Turkey
}

\author{
Investigando os antecedentes de comportamentos inovadores na indústria hoteleira da Turquia
}

\author{
Sima Rahimizhian \\ School of Computing \& Technology, Eastern Mediterranean University, Famagusta, via Mersin 10, Turkey, \\ sima.rahimi@emu.edu.tr \\ Foad Irani \\ Faculty of Tourism, Eastern Mediterranean University, Famagusta, via Mersin 10, Turkey, foad.irani@emu.edu.tr
}

Received: 22.04.2021; Revisions required: 20.09.2021; Accepted: 25.10.2021

\begin{abstract}
The growing focus on the benefits of innovative approaches to gain competitive advantages has inspired studies on the emergence of leadership styles that encourage employees to engage in innovative behaviors. This study examines the relationships between constructive leadership and employees' innovative behavior through the safety climate and employees' proactive behavior within the hospitality context. This paper considers constructive leaders as optimistic managers who regulate desired organizational outcomes with a genuine focus on the highest gains of employees and the organization. The person-environment fit ( $P-E$ fit) theory evaluated prominent organizational factors driving employees' innovative behavior. Two hundred seventy-two valid surveys were obtained among full-time employees of green hotels operating in Turkey. The proposed mediation model was analyzed using partial least squares structural equation modelling. According to the results, full-time employees of green Turkish hotels demonstrated improved, innovative behaviors at work, while a safe climate was paired with proactive behavior under constructive leadership supervision. The theoretical and managerial implications of findings, as well as recommendations for future research, are addressed.
\end{abstract}

Keywords: Constructive leadership, safety climate, proactive behavior, employee's innovative behavior, green hotels.

\section{Resumo}

O foco crescente nos benefícios de abordagens inovadoras para obter vantagens competitivas inspirou estudos sobre o surgimento de estilos de liderança que incentivam os funcionários a envolverem-se em comportamentos inovadores. Este estudo examina as relações entre a liderança construtiva e o comportamento inovador dos funcionários por meio do clima de segurança e o comportamento proactivo dos funcionários no contexto da hotelaria. Este artigo considera os líderes construtivos como gestores otimistas que alcançam os resultados organizacionais desejados através de maiores ganhos para os funcionários e para a organização. A teoria do ajuste pessoa-ambiente avaliou fatores organizacionais impulsionadores do comportamento inovador dos funcionários. Duzentos e setenta e dois inquéritos válidos foram obtidos de colaboradores em tempo integral de hotéis verdes que operam na Turquia. $\mathrm{O}$ modelo de mediação proposto foi analisado por meio de modelagem de equações estruturais de mínimos quadrados parciais. De acordo com os resultados, os colaboradores em tempo integral de hotéis verdes demonstraram comportamentos inovadores e aprimorados no trabalho, num clima seguro combinado com um comportamento proactivo sob supervisão de liderança construtiva. São ainda abordadas as implicações teóricas e práticas dos resultados, bem como recomendações para investigação futura.

Palavras-chave: Liderança construtiva, segurança, comportamento proactivo, comportamento inovador dos colaboradores, hotéis verdes.

\section{Introduction}

In many service sectors, it is widely acknowledged that consumers' perceptions of a firm are frequently connected to their judgments of the performance quality of service personnel. Due to the critical importance of frontline employees in service businesses, managers should view them as the heart of management responsibilities. Managers must recognize the facets of service personnel's jobs that can enhance organizational performance. When it comes to increasing hotels' capability to acquire a competitive edge, the ability of staff to be innovative and creative is critical. Innovative work behavior is required by constantly producing unique ideas in work procedures, strategies, services, or new goods, to create the best results in the hospitality industry (Eliyana \& Christiananta, 2020). Employees' innovative work behaviors or creativity are viewed as the foundation of corporate innovation (Muñoz-Pascual \& Galende, 2020). Thus, further research is required to increase our knowledge of the elements that contribute to high-level individual creative behavior (Saether, 2019).

To supply their services, hospitality service providers rely on various tangible and intangible, technological and nontechnology offers and assets (Goffin \& Mitchell, 2016). Thus, innovation in hospitality represents a combination of technical, non-technological, tangible, and intangible areas that result in enhanced programs and service offerings (Drejer, 2004). In addition, the hospitality sector is adopting sustainable or environmentally friendly operations as critical components of its overall appearance in this quest for innovation. As a result, promoting employees' innovative behavior (INB) is becoming increasingly important in the development of organizations. The prevailing belief is that employees' INB is always helpful in improving processes and is viewed as an essential source of an organization's competitive advantage (Zhang et al., 2018). Hence, the majority of researchers have concentrated on finding variables that encourage inventive behaviors (e.g., BaniMelhem et al., 2018; Sousa et al., 2019), while some others have begun to investigate the impacts of innovation as a valued independent variable (e.g., Khessina et al., 2018). Various studies have focused their research on INB as the outcome of 
organizational culture and resources (Hogan \& Coote, 2014; Irani \& Rahimizhian, 2021; Jeong \& Chun, 2019; Khan et al., 2020) as well as internal and external sources that can influence innovativeness (Ferraris et al., 2017; Segarra-Ciprés et al., 2014). Prior studies have attempted to recognize different types of leadership that might contribute to employees' INB (Alheet et al., 2021; Chen \& Hou, 2016; Hunter et al., 2017; Jaiswal \& Dhar, 2015).

Several recent studies have focused on the antecedents of employees' INB that lead to a deeper understanding of employees' innovativeness. In addition to personality and contextual factors (Bammens, 2016), factors such as work design, organizational assets and job features (Amabile et al., 2018), trust, connection, performance expectations, and image construction are some of the identified antecedents of INB (Yuan \& Woodman, 2010). Other research identifies a strategy, organizational structure, and environment, as well as individual and group competencies, as significant predictors of INB (Mumford \& Licuanan, 2004). Additionally, recent studies have demonstrated the critical impact of effective leadership in developing employees' INB (Arasli et al., 2020; Mokhber et al., 2018). Thus, the demand for organizational innovation has led to a growing emphasis on the role of leaders in determining the nature and success of creative endeavors.

Organizational leadership and leadership theories have long been studied over the years. According to Bass and Stogdill (1990), leadership can be defined as "an interaction among members of a group that involves a structuring or restructuring of the situation and the accompanying perceptions and expectations of members." A leader plays a vital role in motivating people and guiding organizational culture, affecting individual performance and organizational effectiveness (Buil et al., 2019). Leadership is needed at every level of any organization to ensure success. Notably, it has been associated with workplace safety, goal achievement, and efficiency (Christian et al., 2009). Leadership behavior is mainly intended to increase safety within the workplace. In a supportive work environment, employees feel more convinced to do their work without suffering from potential problems as they act more proactively.

Constructive leaders $(\mathrm{CL})$ are supportive leaders who encourage their employees to take more responsibilities (Hadi et al., 2020; Wu \& Parker, 2017). They can also promote employees' proactive behaviors (PB). While the impact of various types of leadership on employees' innovativeness has been well studied, to the best of our knowledge, the relationship between $\mathrm{CL}$ and employees' INB through safety climate (SC) has not been explored yet. The primary intention of a constructive leader is to provide the follower's welfare while considering the fulfillment of organizational goals and efficient use of the organization's resources. Constructive leaders combine human traits such as loyalty, honor, respect, honesty, and fairness with team strengths, including trust, control, success, and trying for the greater good (Burns, 2017). Notably, as innovation contributes to the competitiveness of organizations and destinations, it is a crucial factor for the success of tourism businesses (Hadood \& Irani, 2020). However, the concept of innovation in the tourism industry is questionable as there are various opinions concerning its measurement and application in different sectors and places over time (Carlisle et al., 2013; Krizaj et al., 2014; Mhlanga, 2020).

The person-environment fit ( $P-E$ fit) theory will clarify the overall context of the research since it focuses on the relationship between $\mathrm{CL}$, SC, employees' $\mathrm{PB}$, and INB. According to Choi (2004), P-E fits creative abilities and innovation culture, proposing that personal and environmental factors' cooperation positively affects INB. Constructive leaders actively support subordinates in approaching their job creatively and stimulating people to experiment with innovative solutions to problems. The leaders should provide a workplace atmosphere that promotes a sense of confidence that allows people to thrive by discussing things in a friendly and open manner. This study contributes to the current understanding of how constructive contributions of leaders might change the outcome for the benefit of the decision without much effort wasted. They take a risk, leap, and opportunity with thoughtful offerings to help subordinates produce something unique, better, or freely encourage redesign. Due to the industry's overall influence on the global environment, hospitality businesses are under intense pressure to introduce eco-friendly activities and urge employees to do the same (Gui et al., 2020). Thus, it should be encouraged to investigate how leaders' constructive behavior affects employee performance in green hotels. Researchers in the hospitality industry have discussed that employees in this industry must adapt to quick workplace changes and have recommended appropriate rules and practices for hospitality firms, mainly green hotels (Moin et al., 2021). Specifically, the study's outcomes will benefit managers of green hotels as previous research focused on different types of leadership in the organizational setting rather than investigating its impact in a hospitality setting. To achieve the study's objectives, a research model was created to demonstrate the relationship between $\mathrm{CL}, \mathrm{SC}, \mathrm{PB}$, and INB (figure 1).

\section{Theoretical framework and hypotheses development}

\subsection{Green hotels}

The phrase "green hotel" refers to an environmentally conscious hotel. According to the Green Hotel Association (2007), green hotels are environmentally friendly enterprises that are institutionally supported and encouraged to reduce solid waste and preserve water and electricity, saving the earth while saving money. Since the 1970s, environmental issues have been a constant source of contention (Choi et al., 2015). The current fads focus the attention of various stakeholders on environmental protection (Choi et al., 2015; Irani et al., 2021). With an ever-increasing number of green customers, hotels must change their management to be compatible with society's 
environmental concerns (Han et al., 2010). In response to the matters mentioned earlier, hotels use innovative approaches to improve product and service sustainability. These include employee participation in developing and implementing unique processes, goods, or services, referred to as innovative behavior (Kim \& Lee, 2013). When combined with PB among employees, INB has been an essential component in hospitality organizations to gain a competitive advantage and long-term success (Karatepe et al., 2020; Tuan, 2021).

\subsection{Constructive leadership and safety climate}

According to the literature on P-E fit, a good match between people and their environment (e.g., leader, employees, organization) on relevant dimensions (e.g., task requirements, organizational climate) results in increased commitment, more positive affective experiences at work, and improved performance (Kristof, 1996). Furthermore, P-E fit is a substantial predictor of a range of personal outcomes, including innovative action. Previous leadership studies have attempted to establish environmentally friendly leadership styles from various environmental perspectives, such as transformational leadership (Zhang et al., 2020) and servant leadership (Luu, 2020). However, the impact of different leadership styles such as $\mathrm{CL}$ on green hotels' operations in the hospitality industry is limited. In addition, there have been few empirical studies examining the INB of green hotel leaders and employees and attempting to map the interaction between these principles.

The concept of SC was developed by Zohar (1980) as "a unified set of cognitions regarding the safety aspects of the organization" (p. 101). Accordingly, five fundamental constructs of SC were introduced as safety support of the supervisor, management commitment to safety, colleague safety support, staff safety participation, and competence level. Safety in the workplace is about principal policies and procedures set by an organization to ensure employees' safety, health, and wellbeing. SC is the perception of these policies and procedures that employees share with others in the organization at a given point in time, often related to the accuracy and consistency of the actual conditions with the given policies (Garrick et al., 2014). Several environmental factors might affect workplace safety, but leadership could be the most crucial factor influencing it (Clarke, 2013; Eid et al., 2012; Xu et al., 2021). A positive SC relates to the extent that the organization encourages safety despite the conflict between safety goals and production or time pressure. Previous studies have examined $\mathrm{CL}$ and discussed determinants and outcomes of leadership such as safety and SC (Barling et al., 2002; Eid et al., 2012; Nielsen et al., 2016). Thus, the following proposition has been developed:

H1: CL has a direct positive influence on the workplace's SC.

\subsection{Constructive leadership and proactive behavior}

Beyond expressly set performance objectives, proactive behavior refers to an employee's consciousness, long-termoriented, and continuous service behavior (Rank et al., 2007).
As Wu and Parker (2017) stated, it is not easy to train proactive employees as they produce unknown consequences with high uncertainty. Being proactive means making changes, though those changes are not welcome by supervisors in many situations. Accordingly, a supportive work climate in which employees are encouraged to take risks despite uncertainties is vital to promote $\mathrm{PB}$.

One way to create such a supportive atmosphere within the organization is by having leaders who encourage and empower their subordinates to take on more responsibilities (Wu \& Parker, 2017). Constructive leaders can guide their followers in a way that sustains their effort to reach the goals they set. This style of leadership can foster an environment in which employees feel free to perform proactively. Previous studies have proved that various types of constructive leadership (e.g., transformational leadership) are positively associated with different sorts of PB (Afsar et al., 2019; Wang \& Yang, 2021).

Constructive leaders can cultivate PB by allowing their subordinates to make decisions independently and solve themselves or within the group. Furthermore, since these leaders are more goal-oriented and future-oriented, they are more likely to be perceived as proactive role models who provide a positive atmosphere in which behaving proactively is supported (Schmitt et al., 2016). Thus, we proposed that:

H2: CL has a direct positive influence on employees' PB.

\subsection{Safety climate and employee's innovative behavior}

An appropriate workplace climate plays a vital role in enhancing employees' innovativeness. Employees need to feel safe to take a risk and feel free to voice their problems (Javed et al., 2017). Kessel et al. (2012) state that employees need a SC when talking about new ideas, ignoring traditional ways of operating their tasks. High risk is associated with generating and implementing novel ideas (Mathisen et al., 2012). According to Gong et al. (2012), these new thoughts might fail and fail to achieve desired goals because they might be unhealthy behavior in the organization. Thus, employees need a safe work environment for their risk-taking actions, essential for innovation (Edmondson, 1999). According to the research findings conducted by Bani-Melhem et al. (2018), the workplace climate (which includes moods and happiness) has a significant impact on employees' positive emotions and motivation, motivating them to engage in INB. Moreover, the SC and engagement in creative work tasks indirectly influenced the $\mathrm{CL}$ role in enhancing employee perceptions regarding their serviceinnovation culture (Arasli et al., 2020). Thus, the following proposition has been developed:

H3: The SC has a direct positive influence on employees' INB.

\subsection{Proactive behavior and employee's innovative behavior}

According to Bindl \& Parker (2011), proactive work behavior can be expressed as actions that explicate the empowerment received by upper administration levels. Individuals attempt to 
make changes for further progress, individually or cumulatively. Proactive employees actively initiate changes to attain their goals. These employees successfully explore new ways of doing their job if they have the authority to do so. Proactive employees actively begin changes in achieving their goals. These employees successfully explore new ways of doing their job if they have the power to do so. Proactive employees are required to make a constructive change and redefine their performance to make the necessary efforts to change the conditions, promote new methods, and resolve recent conflicts (Fuller et al., 2006). Previous studies have found a positive linkage between PB and employees' INB (Kim et al., 2009; Rahimizhian \& Irani, 2020; Seibert et al., 2001). People with PB will often produce innovative ideas and will be motivated to explore these thoughts. An employee's desire to achieve a new vision can boost their INB. Therefore, we proposed that:

H4: PB has a direct positive influence on employees' INB.

\subsection{Mediating role of SC between the association of CL and INB}

The companies' desire for innovation emphasized the leadership role as a factor in the success of creative pursuits (Arici \& Uysal, 2021). Leaders have a direct impact on the behaviors of their employees in a variety of ways, including role modeling, goal setting, incentive allocation, and resource distribution (Sagnak, 2012). Moreover, leaders indirectly affect members by encouraging them to try different ways without fear of adverse outcomes. Therefore, leadership style is one of the most important factors affecting organizational innovation. As a result, the importance of leadership in fostering employee creativity has recently gained more attention (Arici \& Uysal, 2021; Chen et al., 2020), not least in terms of constructive leadership (Arasli et al., 2020).

The significance of the SC in the workplace has been widely studied. Previous studies have shown the significant effects of the SC on employees' inventiveness (Tu et al., 2019). On a conceptual level, the $\mathrm{SC}$ is a second-order variable arising from some first-order variables, such as management forces. Given that innovation is widely recognized as a risky and unpredictable activity (Madjar et al., 2011), employees may display innovativeness only when uncertainty is adequately managed. According to uncertainty reduction theory (Lind \& van den Bos, 2002), it is an unpleasant experience that reduces predictability and manageability, hence endangering one's sense of control (Tu et al., 2019). Psychological safety in the workplace refers to a climate that offers individuals enough certainty and stability to be innovative. Given the uncertainty and risks associated with innovation (Madjar et al., 2011), a mediating process that reduces employee uncertainty is reasonable. Thus, we suggest that $\mathrm{CL}$ decreases workplace uncertainty by creating a comfortable environment for employees, encouraging them to perform creatively and innovate. Therefore, we recommend the following mediation hypothesis:

H5: SC mediates the relationship between $\mathrm{CL}$ and INB

\subsection{Mediating role of PB between the association of CL and INB}

Constructive leaders with constructive-oriented leadership traits can support and assist their subordinates in achieving commonly shared goals (Arasli et al., 2020). According to researchers (Ylmaz et al., 2018), services are developed due to employees' interactions with clients, emphasizing the importance of employees' personality characteristics in the service sector. According to $\mathrm{Li}$ et al. (2010), proactive employees develop high-quality exchange connections with their superiors since these partnerships give critical data for self-development. According to Grant and Ashford (2008), PB enable employees to undertake change, and originations frequently rely on proactive workers to foster innovation. In a dynamic work context such as the hospitality sector, where work becomes increasingly dispersed, there is an urge to innovate development, and employees must work independently. Thus, the proactive personality of workers is increasingly crucial to corporate success. Kim et al. (2009) hypothesized that proactive workers are more likely than inactive employees to update their expertise and abilities and identify new working practices. A proactive personality was significantly associated with an individual's inclination for invention, according to Yamak and Eyupoglu (2021). Hence, the following mediation hypothesis has been suggested:

H6: PB mediates the relationship between $\mathrm{CL}$ and INB

Figure 1 - Proposed research model

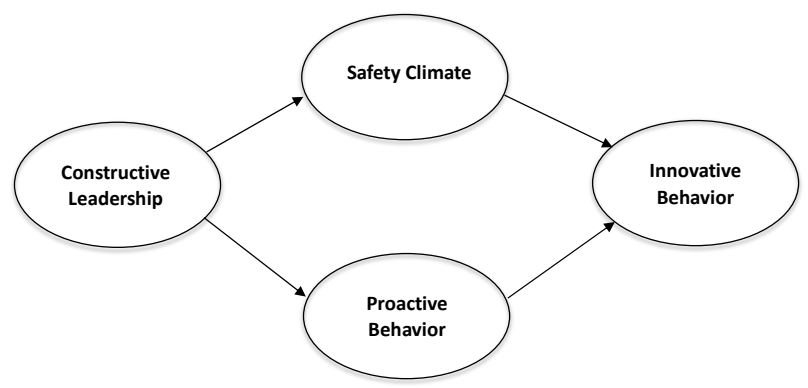

\section{Method}

\subsection{Sample and Procedure}

A questionnaire survey was designed to examine the conceptual model and the hypotheses of the study. A judgmental sampling method was used to collect data from fulltime employees of green hotels located in Turkey. The green globe received UNWTO affiliation, and the sustainable tourism standards are based on the global sustainable tourism council. According to the UNWTO 2020 report, Turkey is listed among the first top ten attractive destinations. According to the Green Globe institution, Turkey's green hotels are seven and vary from 3-stars to 5-stars. There are four 5-star green hotels and one 3star green hotel. The research team requested permission to collect data from the abovementioned green hotel's human resource $(H R)$ directors by explaining the purpose of this research. Thus, all HR directors agreed to conduct the data collection in their green hotels. 
The procedural and statistical remedies were conducted with a two-week time lag to reduce the potential for common method bias (CMB) that can devalue the correlations between the constructs (Podsakoff et al., 2003). The survey asked questions about $\mathrm{CL}, \mathrm{SC}$, and demographics during the first phase. The second period included PB and innovative INB items. The respondents' participation in the survey was voluntary, and the anonymity of the data was guaranteed (Hair et al., 2014). The questionnaires were received in a sealed envelope, and unsealed envelopes were discarded from further consideration in this study. A total of 300 questionnaires were distributed at two periods of time to the participants. First, 283 (94\%) employees participated in the survey. The questionnaires were then sent to the same respondents during the second data collection session. After discarding the incomplete questionnaires, 272 (90.7\%) surveys were retained.

\subsection{Measurement}

The scale items were adapted from relevant literature and were measured using a 5-points Likert scale ranging from 1 (Strongly Disagree) to 5 (Strongly Agree). CL was measured by adopting six items developed by Ekvall and Arvonen (1991). These items measured the employee's perception regarding their leadership's attitude and style. A five-item scale has been utilized to measure the SC by Edmondson (1999). They concentrated on a secured environment at the workplace. PB was examined by adopting four items Tierney, Farmer, and Graen (1999) developed. These items focused on acting in advance of future performance rather than reacting. Finally, INB was measured through six items adapted from $\mathrm{Hu}$ et al. (2009). INB introduces and applies new ideas, products, processes, and procedures to a person's work role, work unit, or organization. All items were initially developed in English and then translated into Turkish using the back-translation method. Two independent multilingual experts participated independently in the translation process to translate the original versions to Turkish and vice-versa (Parameswaran \& Yaprak, 1987; Schaufeli et al., 2006). The measuring instrument's content validity was tested by submitting it to six experts, three of whom were hotel human resource managers and three of whom were assistant professors with specialized education in hospitality management. Some slight changes were made in response to their comments. Furthermore, a pilot test with 20 hotel employees was performed to control the validity of questionnaire items. It demonstrated that the wording, questionnaire items, and sequence of questions appear to be explicit.

\subsection{Data Analysis}

Data analysis was utilized by using version 26 of SPSS and version 2.1.1 of ADANCO. The descriptive statistical analysis was conducted using SPSS, and ADANCO was used to examine the proposed hypothesized model (Ringle et al., 2015). The common method bias (CMB) was assessed by applying SPSS. In this study, the common method variance (CMV) was tested using Harman's single-factor assessment to address the issue of common method bias statistically. The single factor showed $44 \%$. The value is less than the threshold of $50 \%$, which shows that common method bias is not an issue (Chang et al., 2020; Hew et al., 2015). The research model's validity and reliability were evaluated, and the structural model was implemented (Hair et al., 2013). The bootstrapping procedure with 4999 subsamples was used to validate the relevance of all loadings and path coefficients (Hair et al., 2013).

\section{Results}

\subsection{Descriptive Statistics}

This section includes a demographic profile of the respondents. The findings revealed that $52.2 \%$ (142) of the 272 participants were male, and $47.8 \%$ (130) were female. The majority of participants, $56.2 \%$ (153), were between the ages of 28 and 37, while $22.1 \%$ (60) were between the ages of 18 and 27 , and the remaining $21.7 \%$ (59) were between the ages of 38 and $47.59 .9 \%$ (163) were married regarding marital status, while the remaining $40.1 \%$ (109) were single. Regarding educational level, approximately half of the respondents, $49 \%$ (133), had a bachelor's degree, $27.2 \%$ (74) had an associate's degree, and the rest, $23.9 \%$ (65), had a high school diploma. Regarding organizational tenure, $41.5 \%$ (113) had the experience of between 6 to 10 years, 31.5\% (86) had experience of 1 to 5 years, while the remaining $27 \%$ (73) had less than a year of experience.

Table 1 - Respondents' Profile $(\mathbf{n}=\mathbf{2 7 2})$

\begin{tabular}{|l|c|c|}
\hline & Frequency & \% \\
\hline Age & & \\
\hline $18-27$ & 60 & 22.1 \\
\hline $28-37$ & 153 & 56.2 \\
\hline $38-47$ & 59 & 21.7 \\
\hline 47 and above & & \\
\hline Gender & & \\
\hline Male & 142 & 52.2 \\
\hline Female & 130 & 47.8 \\
\hline Marital Status & & \\
\hline Single & 109 & 40.1 \\
\hline Married & 163 & 59.9 \\
\hline Education & & \\
\hline High School & 65 & 23.9 \\
\hline Associate Degree & 74 & 27.2 \\
\hline Bachelor Degree & 133 & 49 \\
\hline Master Degree & & \\
\hline Organizational Tenure & & \\
\hline Less than one year & 73 & 27 \\
\hline 1-5 years & 86 & 31.5 \\
\hline $6-10$ years & 113 & 41.5 \\
\hline Longer than ten years & & \\
\hline & & \\
\hline
\end{tabular}

\subsection{Psychometric Properties}

The confirmatory factor analysis (CFA) was conducted in ADANCO2.1.1, and the adequacy for the data was confirmed using the following factors: indicator loadings, AVE, Cronbach's 
alpha ( $\alpha)$, Jöreskog's $\rho(\rho C)$, and Dijkstra-Henseler's $\rho(\rho A)$ indicator reliabilities (Dijkstra \& Henseler, 2015). The reliability and internal consistency of the constructs are represented in Table 2; the Cronbach Alpha ( $\alpha$ ) and composite reliability (CR) cut-off level are to be higher than 0.7 for the constructs to be reliable (Hair et al., 2013). Thus, the current study's constructs met this condition. Also, Table 2 shows the KMO tests for our research constructs, which range between 0.809 to 0.867 , indicating substantial homogeneity since the results are between 0.8 and 0.9 (Morocco, 2011).

The indicators are loaded adequately under their underlying constructs. For instance, the six leadership constructs had loadings ranging from 0.721 to 0.834 . The loadings of SC indicators ranged from 0.742 to 0.883 ; PB loadings ranged from 0.813 to 0.890 , and INB loadings ranged from 0.745 to 0.856 . Overall, all the indicator loadings of the constructs under investigation ranged from 0.721 to 0.890 , suggesting initial evidence of convergent validity. Furthermore, the AVE values for all the constructs were above 0.5 , which is the required threshold (Hair et al., 2013).

To assure the reliability of the scales, we used a combination of Cronbach's alpha criterion and Jöreskog's $\rho(\rho C)$, and DijkstraHenseler's $\rho(\rho A)$ indicator reliabilities scores. As a rule of thumb, a reliable scale will have values of 0.7 or more. As shown in Table 1, all the constructs met the threshold, which confirms the scale reliability (Henseler et al., 2016).

Table 2 - Measurement Model Evaluation

\begin{tabular}{|c|c|c|c|c|c|c|c|}
\hline Items & Loadings & KMO tests & $(\rho \mathrm{A})$ & $(\rho C)$ & $(\alpha)$ & AVE & CR \\
\hline Constructive Leadership & & 0.846 & 0.87 & 0.89 & 0.86 & 0.58 & 0.89 \\
\hline CL1 & 0.752 & & & & & & \\
\hline $\mathrm{CL2}$ & 0.721 & & & & & & \\
\hline CL3 & 0.736 & & & & & & \\
\hline CL4 & 0.834 & & & & & & \\
\hline CL5 & 0.770 & & & & & & \\
\hline CL6 & 0.754 & & & & & & \\
\hline Safety Climate & & 0.867 & 0.90 & 0.92 & 0.90 & 0.72 & 0.93 \\
\hline SC1 & 0.869 & & & & & & \\
\hline $\mathrm{SC2}$ & 0.863 & & & & & & \\
\hline SC3 & 0.874 & & & & & & \\
\hline SC4 & 0.883 & & & & & & \\
\hline SC5 & 0.742 & & & & & & \\
\hline Proactive Behavior & & 0.809 & 0.86 & 0.90 & 0.86 & 0.70 & 0.90 \\
\hline PB1 & 0.830 & & & & & & \\
\hline PB2 & 0.819 & & & & & & \\
\hline PB3 & 0.890 & & & & & & \\
\hline PB4 & 0.813 & & & & & & \\
\hline Innovative Behavior & & 0.863 & 0.89 & 0.91 & 0.89 & 0.64 & 0.91 \\
\hline INB1 & 0.808 & & & & & & \\
\hline INB2 & 0.787 & & & & & & \\
\hline INB3 & 0.773 & & & & & & \\
\hline INB4 & 0.856 & & & & & & \\
\hline INB5 & 0.811 & & & & & & \\
\hline INB6 & 0.745 & & & & & & \\
\hline
\end{tabular}

Note: $\rho A$ implies Dijkstra-Henseler's rho, $\rho$ C implies Jöreskog's rho, $\alpha$ implies Cronbach's alpha, AVE implies average variance extracted, CR implies composite reliability.

Source: Authors' elaboration.

Discriminant validity was assessed using a combination of the widely accepted conventional criterion of Fornell and Larcker (1981) in conjunction with the Heterotrait-Monotrait ratio criterion. As provided in Table 3, the study results confirmed the discriminant validity of all constructs of interest. Based on
Fornell and Larcker's requirement, the AVE of all constructs is higher than the squared correlations of the constructs. Furthermore, as required by the HTMT ratio, all inter-construct correlation values were below the cut-off level of 0.9 . 
Table 3 - Evidence of Discriminant Validity

\begin{tabular}{|l|c|c|c|c|}
\hline \multicolumn{1}{|c|}{ HTMT Ratio Criterion } & & & & \\
\hline Construct & CL & SC & PB & INB \\
\hline CL & & & & \\
\hline SC & 0.6045 & & & \\
\hline PB & 0.4691 & 0.6211 & & \\
\hline INB & 0.5666 & 0.7171 & 0.8110 & \\
\hline Fornell and Larcker Criterion & & & & INB \\
\hline Construct & $\mathbf{C L}$ & $\mathbf{S C}$ & PB & \\
\hline CL & $\mathbf{0 . 5 8 0 8}$ & & & \\
\hline SC & 0.3003 & $\mathbf{0 . 7 1 8 8}$ & & $\mathbf{0 . 6 3 5 7}$ \\
\hline PB & 0.1722 & 0.3107 & $\mathbf{0 . 7 0 3 1}$ & \\
\hline INB & 0.2536 & 0.4497 & 0.5094 & \\
\hline
\end{tabular}

Note: Squared correlations; AVE in the diagonal, $\mathrm{CL}$ implies constructive leadership, SC implies safety climate, $\mathrm{PB}$ implies proactive behavior, and INB implies innovative behavior.

Source: Authors' elaboration.

\subsection{Results of Hypothesized Relationship}

The research model proposed a direct impact of $\mathrm{CL}$ on employees' SC and PB. Likewise, the model proposed the direct effect of SC on INB as well as PB on INB. Moreover, the indirect effect of $C L$ on INB through SC and PB was examined. Thus hypotheses 1 and 2 postulated that $\mathrm{CL}$ exerts a positive and significant impact on employees' SC and PB. As reported in Table 4, the direct effects of $C L$ were positive and significant. Specifically, $C L$ exerts $\left(\beta=0.55,14.08^{* * *}\right.$ ) on $S C$ and $(\beta=0.41$, $7.72^{* * *}$ ) on $\mathrm{PB}$. Thus, hypotheses 1 and 2 that suggested the positive and significant impact of $\mathrm{CL}$ on $\mathrm{SC}$ and $\mathrm{PB}$ are supported.

Table 4 - Result of Direct, Indirect and Total effects

\begin{tabular}{|c|c|c|c|c|c|}
\hline Effect & Beta & t-value & ${\text { Cohen's } \mathbf{f}^{\mathbf{2}}}^{\mathbf{R}^{\mathbf{2}}}$ & Remark $^{\text {Supported }}$ \\
\hline CL -> SC & 0.55 & $14.08^{* * *}$ & 0.43 & & Supported \\
\hline CL -> PB & 0.41 & $7.72^{* * *}$ & 0.21 & Supported \\
\hline SC -> INB & 0.39 & $7.53^{* * *}$ & 0.28 & Supported \\
\hline PB -> INB & 0.49 & $9.17^{* * *}$ & 0.44 & 0.30 & \\
\hline SC & & & & 0.17 & \\
\hline PB & & & & 0.62 & \\
\hline
\end{tabular}

Note: ${ }^{* *} \mathrm{P} \leq 0.001$, Bootstrapped resample size $9.999, \mathrm{CL}$ implies constructive leadership, SC implies safety climate, PB implies proactive behavior, INB implies innovative behavior.

Source: Authors' elaboration.

Hypotheses 3 and 4 proposed that the direct impact of SC on INB and PB on INB were also empirically supported. The path coefficient of the link between SC and INB $\left(\beta=0.39,7.53^{* * *}\right)$ showed a significant and positive association between $\mathrm{SC}$ and
INB. Thus, hypothesis 3 is supported. Hypothesis 4 investigated the path through which PB impacts INB and yielded a path coefficient value of $\left(\beta=0.49,9.17^{* * *}\right)$. Thus, hypothesis 4 is supported.

Table 5 - Mediation Effects

\begin{tabular}{|c|c|c|c|c|c|c|c|c|}
\hline IV & MV & DV & Effect of IV on MV & Effect of MV on DV & Direct effect & Indirect effect & Total effect & CL-CU \\
\hline CL & SC & INB & 0.548 & 0.396 & 0.421 & 0.217 & 0.638 & $0.325-0.453$ \\
\hline CL & PB & INB & 0.415 & 0.493 & 0.421 & 0.204 & 0.626 & $0.349-0.503$ \\
\hline
\end{tabular}

Notes: IV, independent variable; MV, mediating variable; DV, dependent variable, CL: Constructive Leadership, INB: Innovative Behavior, SC: Safety Climate, PB: Proactive Behavior, $\mathrm{CL}=2.5 \%$ lower percentile bootstrap quantiles, $\mathrm{CU}=97.5 \%$ upper percentile bootstrap quantiles.

The indirect effects of $\mathrm{CL}$ on INB through SC and PB were proposed in hypotheses 5 and 6 , respectively. The hypotheses mentioned above were also statistically supported (see Table 5). According to the findings, full-time employees of green hotels have a more vital link with INB via a SC and PB.

The direct effects in the model are further supported by the determination coefficient $\left(R^{2}\right)$ and Cohen's effect size $\left(f^{2}\right)$. As reported, CL had a substantial predictive effect power on INB with about $0.62 \%$ variance. The determination coefficient $\left(R^{2}\right)$ and Cohen's effect size $\left(f^{2}\right)$ support the direct effects. As reported, CL had a substantial predictive effect power on INB with about $0.62 \%$ variance. Also, according to the result of $\mathrm{f}^{2}, \mathrm{CL}$ exerted a medium impact on $\mathrm{PB}$, and $\mathrm{SC}$ exerted a medium effect on INB. Respectively, CL and PB exerted a more potent influence on SC and INB. 
Figure 2 - Items loading, $\boldsymbol{\beta}$ and $\mathbf{R}^{2}$ values

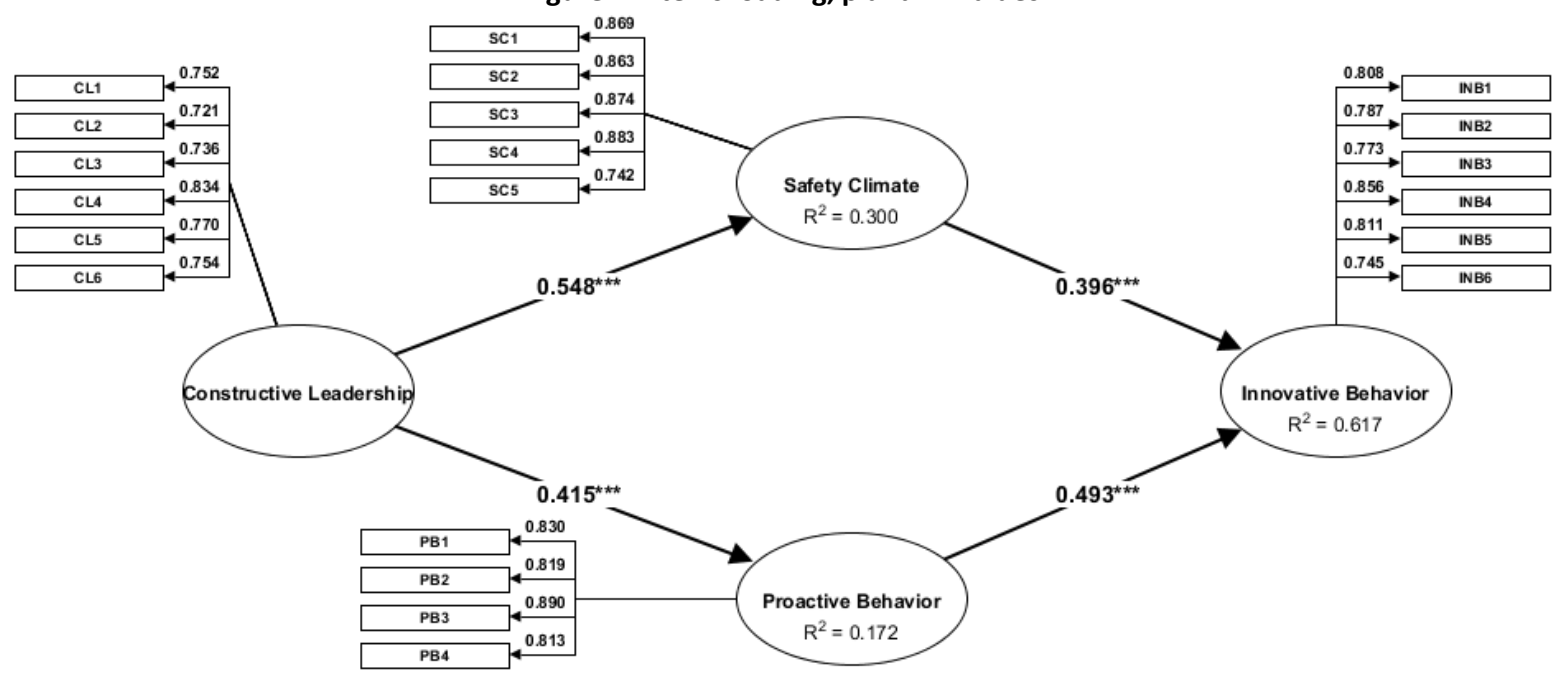

\section{Discussion and conclusion}

The current study investigates the relationship between $\mathrm{CL}$ and employees to understand how positive leadership approaches might drive employees to seek innovative solutions to environmental concerns at work. Drawing from the P-E fit framework, we evaluated and found evidence of the relationships between $\mathrm{CL}$ and employees' INB among green hotel employees in Turkey, both directly and indirectly, via SC and $\mathrm{PB}$ practices. $\mathrm{CL}$ has been shown to have a notable effect on workers' innovative work behaviors. Although earlier research has demonstrated that $\mathrm{CL}$ has a significant role in enhancing service innovative behavior (Arasli et al., 2020), the link between the two has received less attention among employees of green hotels. Furthermore, among different leadership styles, research on the effectiveness of $\mathrm{CL}$ in the hospitality context is still very scarce and inconclusive. This study's findings add to the body of empirical data on the efficacy of $C L$ in the hospitality setting and, as a result, in the fields of green hotel management and leadership studies.

\subsection{Theoretical implications}

Consistent with a study by Dedahanov et al. (2019), we discussed that constructive leaders could positively affect the SC and encourage their subordinates to act proactively to produce more innovative outcomes. Therefore, we anticipated constructive leadership as one of the leadership types that can be considered a vital factor in enhancing the organization's performance in the hospitality industry. Consequently, the study's notable contribution lies in addressing critical aspects of leadership, particularly constructive leadership, which confirms previous studies' findings on the impact of this variable in producing positive behavioral consequences such as employees' INB in the context of hospitality. It provides hospitality management with a more profound comprehension of improving quality by increasing the innovativeness among the employees. A constructive leader who approaches responsibilities positively helps employees become available, reliable, and efficient and can be adaptable and quickly change tasks using their creativity. Innovative employees are particularly needed in unpredictable, dynamic, and highly competitive business settings such as the hospitality industry. The findings proved that constructive leaders positively and significantly produce a safe environment that leads to innovative performance. Moreover, the significant direct and indirect effects of $C L$ on employees' INB demonstrate that the outcomes of the current study add to hospitality knowledge in several ways. Our findings extend prior research findings such that it impacts employees' INB through an underlying process in hospitality organizations, specifically green hotels.

We extend this study by demonstrating that constructive leaders are needed for creative workers in the hospitality sector. The study's results regarding the mediating role of SC between $C L$ and INB relationships imply that safety perceptions at work increase employees' INB since employees believe they are safe and have a higher sense of well-being when working for supportive and moral supervisors. A constructive leader's standards of support and inspiration have a beneficial effect on employees' trust and psychological well-being (Conchie, 2014). Employees who work for such leaders believe it is eligible to work for them since they do not backstab. Additionally, they are not in danger of losing their jobs and have higher engagement, responsibility, and autonomy at work (Moin et al., 2021). Thus, it improves both the $\mathrm{SC}$ and the innovative culture of hospitality businesses.

Our first finding supports the significant relationship between $\mathrm{CL}$ and SC in expected directions. This result is in line with a study by Arasli et al. (2020). SC is a means to evaluate how employees feel about their corporation's safety culture at any given point in time. The term "safety climate" refers to employees' collective opinions of their employers' and leaders' attention to safety. Additionally, it serves as a focal point for implementing improvements to enhance workplace safety and employees' well-being that result in better work performance. 
The findings of this study also demonstrate that $\mathrm{PB}$ is a significant predictor of INB in the hotel industry.

Additionally, hotels seeking to foster INB may be more effective by hiring proactive personnel and implementing appropriate selection procedures. Moreover, hotel managers could participate in similar motivational activities that constructive leaders do to encourage employees' PB. Also, this study contributes to the literature by being one of the few to suggest and validate the beneficial effects of $\mathrm{CL}$ on $\mathrm{PB}$. Thus, the current study contributes to a better understanding of the link between $\mathrm{CL}$ and $\mathrm{PB}$, filling a gap in the related literature. Additionally, the study demonstrates that $\mathrm{CL}$ affects employees' $\mathrm{PB}$, with $\mathrm{PB}$ acting as a mediator. This finding is significant because it shows how leaders' constructive personalities support hotel workers' $\mathrm{PB}$, influencing their innovative work behaviors.

\subsection{Practical implications}

With economies facing difficulties and attempting to remain competitive, companies are becoming more interested in innovation, which results in increased economic efficiency. Businesses can improve their innovation capabilities by empowering employees to generate new ideas. The results of this study will serve as a guide for leaders seeking to improve their organization's innovative work behavior.

A leader's leadership style may inspire workers to demonstrate INB through SC and PB. An optimistic and constructive leader will improve the $\mathrm{SC}$ in the workplace. As a result, hospitality managers must understand the impact of their leadership style on the workplace climate that affects employees' wellbeing. Hence, they should act constructively toward employees by adhering to $\mathrm{CL}$ techniques and remaining aware of the significant connection between leadership style and employees' performance. In a dynamic and unpredictable work environment, it can become an increasing concern for managers and leaders to establish a safe work environment that their subordinates can offer and share novel ideas. Uncertainty issues can limit INB, which has an adverse influence on both employee and organizational outcomes. As a result, leadership styles that foster a healthy environment and psychological well-being are highly significant in the highly competitive and diverse hospitality industry. Therefore, it is indispensable to assess the manager's approaches to ensure that the SC provided by managers is perceived positively by the employees at the workplace. A SC can enact the PB of employees that results in outcomes such as creativity. A proper leadership approach, particularly constructive leadership, encourages employees to express their ideas in a complex work environment.

Within the particular context of this study, constructive leaders should cultivate a green environment if they want their workers to engage in green practices. Employees should be given clear messages, and such a vision should be expressed by leaders and organizations who emphasize the importance of sustainable development aspirations in the workplace.
The hospitality industry might benefit from hiring supervisors who are aware of the situational antecedents of INB. Constructive leaders who provide autonomy and support to their subordinates could stimulate such behavior in their employees. Moreover, as the foremost hospitality industry organizations, hotels should reinstruct their job recruiting process by assessing proactive personality job applicants. Meanwhile, managers in the hospitality industry should be aware of their leadership style's influence on the SC in the workplace.

Furthermore, findings show that empowering employees to actively make changes while creating a safe work environment assists leaders in promoting new ideas and generations. Indeed, leaders who generally show interest in employees' ideas and try to keep them motivated can increase the INB of their subordinates. Thus, managers following $\mathrm{CL}$ practices need to know that maintaining a feedback culture, support for implementing better ideas, promising rewards, and providing resources for implementation can lead to innovation achievement.

\subsection{Limitations and future suggestions}

There could be some limitations to this study, as with any other research. There is a need for further research to study other determinants apart from SC and PB that may trigger employees' INB in a work setting in the hospitality industry. Since this study explores the influence of constructive leadership through SC and PB on employees' INB, it may be helpful to expand the author's view by considering the same framework in other sectors of the hospitality industry to have a better understanding that can positively influence the outcomes for hospitality industry performances such as gaining competitive advantages. The current study is aimed at employees working in workplaces such as hotels; the same approach can be applied among the managers of different sectors in the hospitality industry. Therefore, it is suggested to conduct a similar study among different hierarchical levels of management to explore the effect of constructive leadership on the INB of managers. Finally, the connection between SC and PB was not investigated in the current study. Therefore, future studies are recommended to explore the effect of the SC on PB within the hospitality context.

\section{References}

Afsar, B., Masood, M., \& Umrani, W. A. (2019). The role of job crafting and knowledge sharing on the effect of transformational leadership on innovative work behavior. Personnel Review, 48(5), 1186-1208. https://doi.org/10.1108/PR-04-2018-0133

Alheet, A., Adwan, A., Areiqat, A., Zamil, A., \& Saleh, M. (2021). The effect of leadership styles on employees' innovative work behavior. Management Science Letters, 11(1), 239-246. https://doi.org/10.5267/j.msl.2020.8.010

Amabile, T. M., \& Fisher, C. M. (2000). Stimulate creativity by fueling passion. In Edwin A. Locke, Handbook of principles of organizational behavior (pp. 331-341), Willey Online Library. https://doi.org/10.1002/9781405164047.ch23 
Amabile, T. M., Collins, M. A., Conti, R., Phillips, E., Picariello, M., Ruscio, J., \& Whitney, D. (2018). Creativity in context: Update to the social psychology of creativity. Routledge.

Arasli, H., Arici, H. E., \& Kole, E. (2020). Constructive leadership and employee innovative behaviors: a serial mediation model. Sustainability, 12(7),

2592. https://doi.org/10.3390/su12072592

Arici, H. E., \& Uysal, M. (2021). Leadership, green innovation, and green creativity: a systematic review. The Service Industries Journal, 1-41. https://doi.org/10.1080/02642069.2021.1964482

Bammens, Y. P. (2016). Employees' innovative behavior in social context: A closer examination of the role of organizational care. Journal of Product Innovation Management, 33(3), 244-259. https://doi.org/10.1111/jpim.12267

Bani-Melhem, S., Zeffane, R., \& Albaity, M. (2018). Determinants of employees' innovative behavior. International Journal of Contemporary Hospitality Management, 30(3), 1601-1620. https://doi.org/10.1108/IJCHM-02-2017-0079

Barling, J., Loughlin, C., \& Kelloway, E. K. (2002). Development and test of a model linking safety-specific transformational leadership and occupational safety. Journal of Applied Psychology, 87(3), 488-496. https://doi.org/10.1037/0021-9010.87.3.488

Bass, B. M., \& Stogdill, R. M. (1990). Bass \& Stogdill's handbook of leadership: Theory, research, and managerial applications. Simon and Schuster.

Bindl, U. K., \& Parker, S. K. (2011). Proactive work behavior: Forwardthinking and change-oriented action in organizations. In APA handbook of industrial and organizational psychology, Vol 2: Selecting and developing members for the organization. (pp. 567-598). American Psychological Association.

Buil, I., Martínez, E., \& Matute, J. (2019). Transformational leadership and employee performance: The role of identification, engagement and proactive personality. International Journal of Hospitality Management, 77, 64-75. https://doi.org/10.1016/j.ijhm.2018.06.014

Burns, W. A. (2017). A descriptive literature review of harmful leadership styles: Definitions, commonalities, measurements, negative impacts, and ways to improve these harmful leadership styles. Creighton Journal of Interdisciplinary Leadership, 3(1), 33-52. http://dx.doi.org/10.17062/CJIL.v3i1.53

Carlisle, S., Kunc, M., Jones, E., \& Tiffin, S. (2013). Supporting innovation for tourism development through multi-stakeholder approaches: Experiences from Africa. Tourism Management, 35, 59-69. https://doi.org/10.1016/j.tourman.2012.05.010

Carmeli, A., Sheaffer, Z., Binyamin, G., Reiter-Palmon, R., \& Shimoni, T. (2014). Transformational leadership and creative problem-solving: The mediating role of psychological safety and reflexivity. The Journal of Creative Behavior, 48(2), 115-135. https://doi.org/10.1002/jocb.43

Chang, Y., Hou, R. J., Wang, K., Cui, A. P., \& Zhang, C. B. (2020). Effects of intrinsic and extrinsic motivation on social loafing in online travel communities. Computers in Human Behavior, 109, 106360. https://doi.org/10.1016/j.chb.2020.106360

Chen, A. S. Y., \& Hou, Y. H. (2016). The effects of ethical leadership, voice behavior and climates for innovation on creativity: A moderated mediation examination. The Leadership Quarterly, 27(1), 1-13.

Chen, L., Wadei, K. A., Bai, S., \& Liu, J. (2020). Participative leadership and employee creativity: a sequential mediation model of psychological safety and creative process engagement. Leadership \& Organization Development Journal, 41(6), 741-759. https://doi.org/10.1108/LODJ07-2019-0319

Chénard-Poirier, L. A., Morin, A. J., Boudrias, J. S., \& Gillet, N. (2021). The combined effects of destructive and constructive leadership on thriving at work and behavioral empowerment. Journal of Business and Psychology, 1-17. https://doi.org/10.1007/s10869-021-09734-7

Choi, H., Jang, J., \& Kandampully, J. (2015). Application of the extended VBN theory to understand consumers' decisions about green hotels. International Journal of Hospitality Management, 51, 87-95. https://doi.org/10.1016/j.ijhm.2015.08.004

Choi, J. N. (2004). Person-environment fit and creative behavior: Differential impacts of supplies-values and demands-abilities versions of fit. Human Relations, 57(5), 531-552.

Christian, M. S., Bradley, J. C., Wallace, J. C., \& Burke, M. J. (2009). Workplace safety: a meta-analysis of the roles of person and situation factors. Journal of Applied Psychology, 94(5), 1103-27. https://doi.org/10.1037/a0016172

Clarke, S. (2013). Safety leadership: A meta-analytic review of transformational and transactional leadership styles as antecedents of safety behaviours. Journal of Occupational and Organizational Psychology, 86(1), 22-49.

Colbert, A. E., Barrick, M. R., \& Bradley, B. H. (2014). Personality and leadership composition in top management teams: Implications for organizational effectiveness. Personnel Psychology, 67(2), 351-387.

De Jong, J. P., \& Den Hartog, D. N. (2007). How leaders influence employees' innovative behaviour. European Journal of innovation management, 10(1), 41-64

Dedahanov, A. T., Bozorov, F., \& Sung, S. (2019). Paternalistic leadership and innovative behavior: Psychological empowerment as a mediator. Sustainability, 11(6),

https://doi.org/10.3390/su11061770

Dijkstra, T. K., \& Henseler, J. (2015). Consistent partial least squares path modeling. MIS quarterly, 39(2), 297-316.

Drejer, I. (2004). Identifying innovation in surveys of services: A Schumpeterian perspective. Research policy, 33(3), 551-562.

Edmondson, A. (1999). Psychological safety and learning behavior in work teams. Administrative science quarterly, 44(2), 350-383.

Eid, J., Mearns, K., Larsson, G., Laberg, J. C., \& Johnsen, B. H. (2012). Leadership, psychological capital and safety research: Conceptual issues and future research questions. Safety science, 50(1), 55-61.

Ekvall, G., \& Arvonen, J. (1991). Change-centered leadership: An extension of the two-dimensional model. Scandinavian Journal of Management, 7(1), 17-26.

Eliyana, A., \& Christiananta, B. (2020). Enhancing innovative work behavior in the hospitality industry: Empirical research from East Java, Indonesia. International Journal of Business and Society, 21(1), 96-110.

Ferraris, A., Santoro, G., \& Dezi, L. (2017). How MNC's subsidiaries may improve their innovative performance? The role of external sources and knowledge management capabilities. Journal of Knowledge Management, 21(3), pp. 540-552. https://doi.org/10.1108/JKM-092016-0411

Fornell, C., \& Larcker, D. F. (1981). Structural equation models with unobservable variables and measurement error: Algebra and statistics. Journal of Marketing Research, 18(3), 382-388. https://doi.org/10.2307/3150980

Fuller, J. B., Marler, L. E., \& Hester, K. (2006). Promoting felt responsibility for constructive change and proactive behavior: Exploring aspects of an elaborated model of work design. Journal of Organizational Behavior, 27(8), 1089-1120.

Garrick, A., Mak, A. S., Cathcart, S., Winwood, P. C., Bakker, A. B., \& Lushington, K. (2014). Psychosocial safety climate moderating the effects of daily job demands and recovery on fatigue and work engagement. Journal of Occupational and Organizational Psychology, 87(4), 694-714.

Goffin, K., \& Mitchell, R. (2016). Innovation management: effective strategy and implementation. Macmillan International Higher Education.

Gong, Y., Cheung, S. Y., Wang, M., \& Huang, J. C. (2012). Unfolding the proactive process for creativity: Integration of the employee proactivity, information exchange, and psychological safety perspectives. Journal of Management, 38(5), 1611-1633. 
Grant, A. M., Ashford, S. J. (2008). The dynamics of proactivity at work. Research in Organizational Behavior, 28, 3-34. https://doi.org/10.1016/j.riob.2008.04.002

Gui, C., Luo, A., Zhang, P., \& Deng, A. (2020). A meta-analysis of transformational leadership in hospitality research. International Journal of Contemporary Hospitality Management, 32(6), 2137-2154. https://doi.org/10.1108/IJCHM-05-2019-0507

Hadi, D. M., Irani, F., \& Gökmenoğlu, K. K. (2020). External determinants of the stock price performance of tourism, travel, and leisure firms: evidence from the United States. International Journal of Hospitality \& Tourism Administration,

1-17. https://doi.org/10.1080/15256480.2020.1842838

Hadood, A. A. A., \& Irani, F. (2020). Impact of economic sentiment and economic policy uncertainty on travel and leisure stock return. Journal of Hospitality and Tourism Insights, 4(1), 98-120. https://doi.org/10.1108/JHTI-05-2020-0070

Hair Jr, J. F., Sarstedt, M., Hopkins, L., \& Kuppelwieser, V. G. (2014). Partial least squares structural equation modeling (PLS-SEM): An emerging tool in business research. European Business Review, 26(2), 106-121. https://doi.org/10.1108/EBR-10-2013-0128

Hair, J. F., Ringle, C. M., \& Sarstedt, M. (2013). Partial least squares structural equation modeling: Rigorous applications, better results and higher acceptance. Long range planning, 46(1-2), 1-12.

Han, H., Hsu, L. T. J., \& Sheu, C. (2010). Application of the theory of planned behavior to green hotel choice: Testing the effect of environmental friendly activities. Tourism management, 31(3), 325-334.

Henseler, J., Hubona, G., \& Ray, P. A. (2016). Using PLS path modeling in new technology research: updated guidelines. Industrial Management \& Data Systems, 116(1), 2-20. https://doi.org/10.1108/IMDS-09-2015-0382

Henseler, J., Ringle, C. M., \& Sarstedt, M. (2015). A new criterion for assessing discriminant validity in variance-based structural equation modeling. Journal of the Academy of Marketing Science, 43(1), 115-135.

Hew, J. J., Lee, V. H., Ooi, K. B., \& Wei, J. (2015). What catalyses mobile apps usage intention: an empirical analysis. Industrial Management \& Data Systems, 115(7), 1269-1291. https://doi.org/10.1108/IMDS-012015-0028

Hogan, S. J., \& Coote, L. V. (2014). Organizational culture, innovation, and performance: A test of Schein's model. Journal of Business Research, 67(8), 1609-1621.

Hu, M. L. M., Horng, J. S., \& Sun, Y. H. C. (2009). Hospitality teams: Knowledge sharing and service innovation performance. Tourism Management, 30(1), 41-50.

Hunter, S. T., Cushenbery, L. D., \& Jayne, B. (2017). Why dual leaders will drive innovation: Resolving the exploration and exploitation dilemma with a conservation of resources solution. Journal of

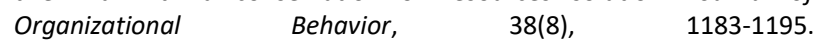
https://doi.org/10.1002/job.2195

Irani, F., \& Rahimizhian, S. (2021). Exploring the association among intention to study abroad, destination brand awareness, WOM, and destination choice of international students of North Cyprus. Presentation at the Managing Tourism Across Continents (MTCON'21) Conference, 1-3 April 2021, Online.

Irani, F., Ozturen, A., \& Akhshik, A. (2021). Host-tourist interactions and residents' attitudes towards sustainable tourism development. In A. Decrop, A. Correia, A. Fyall, \& M. Kozak (Eds.), Sustainable and collaborative tourism in a digital world (pp. 123-134). Oxford: Goodfellow Publishers.

Jafri, M. H. (2010). Organizational commitment and employee's innovative behavior: A study in retail sector. Journal of Management Research, 10(1), 62-68.

Jaiswal, N. K., \& Dhar, R. L. (2015). Transformational leadership, innovation climate, creative self-efficacy and employee creativity: A multilevel study. International Journal of Hospitality Management, 51, 30-41.

Javed, B., Naqvi, S. M. M. R., Khan, A. K., Arjoon, S., \& Tayyeb, H. H. (2017). Impact of inclusive leadership on innovative work behavior: The role of psychological safety. Journal of Management \& Organization, 25(1), 117-136. https://doi.org/10.1017/jmo.2017.3

Jeong, D. U., \& Chun, B. J. (2019). The mediation effect of trust and communication on relationship between organizational culture and innovative behavior: Focused on manufacturing business. Asia-Pacific Journal of Business, 10(1), 39-54.

Karatepe, O. M., Aboramadan, M., \& Dahleez, K. A. (2020). Does climate for creativity mediate the impact of servant leadership on management innovation and innovative behavior in the hotel industry? International Journal of Contemporary Hospitality Management, 32(8), 2497-2517. https://doi.org/10.1108/IJCHM-03-2020-0219

Kessel, M., Hannemann-Weber, H., \& Kratzer, J. (2012). Innovative work behavior in healthcare: The benefit of operational guidelines in the treatment of rare diseases. Health policy, 105(2), 146-153.

Khan, M. A., Ismail, F. B., Hussain, A., \& Alghazali, B. (2020). The interplay of leadership styles, innovative work behavior, organizational culture, and organizational citizenship behavior. SAGE Open, 10(1). https://doi.org/10.1177/2158244019898264

Khaola, P., \& Coldwell, D. (2019). Explaining how leadership and justice influence employee innovative behaviours. European Journal of Innovation Management, 22(1), 193-212. https://doi.org/10.1108/EJIM-08-2017-0103

Khessina, O. M., Goncalo, J. A., \& Krause, V. (2018). It's time to sober up: The direct costs, side effects and long-term consequences of creativity and innovation. Research in Organizational Behavior, 38, 107-135.

Kim, T. T., \& Lee, G. (2013). Hospitality employee knowledge-sharing behaviors in the relationship between goal orientations and service innovative behavior. International Journal of Hospitality Management, 34, 324-337.

Kim, T. Y., Hon, A. H., \& Crant, J. M. (2009). Proactive personality, employee creativity, and newcomer outcomes: A longitudinal study. Journal of Business and Psychology, 24(1), 93-103.

Kristof, A. L. (1996). Person-organization fit: An integrative review of its conceptualizations, measurement, and implications. Personnel Psychology, 49(1), 1-49.

Krizaj, D., Brodnik, A., \& Bukovec, B. (2014). A tool for measurement of innovation newness and adoption in tourism firms. International Journal of Tourism Research, 16(2), 113-125.

Li, N., Liang, J., \& Crant, J. M. (2010). The role of proactive personality in job satisfaction and organizational citizenship behavior: a relational perspective. Journal of applied psychology, 95(2), 395.

Lind, E. A., \& Van den Bos, K. (2002). When fairness works: Toward a general theory of uncertainty management. Research in Organizational Behavior, 24, 181-223.

Lundmark, R., Nielsen, K., Hasson, H., von Thiele Schwarz, U., \& Tafvelin, S. (2020). No leader is an island: contextual antecedents to line managers' constructive and destructive leadership during an organizational intervention. International Journal of Workplace Health Management, 13(2), 173-188. https://doi.org/10.1108/IJWHM-052019-0065

Luu, T. T. (2020). Integrating green strategy and green human resource practices to trigger individual and organizational green performance: The role of environmentally-specific servant leadership. Journal of Sustainable Tourism, 28(8), 1193-1222.

Madjar, N., Greenberg, E., \& Chen, Z. (2011). Factors for radical creativity, incremental creativity, and routine, noncreative performance. Journal of Applied Psychology, 96(4), 730.

Maroco, J. (2011). Análise estatística com o SPSS Statistics. Wook.

Mathisen, G. E., Einarsen, S., \& Mykletun, R. (2012). Creative leaders promote creative organizations. International Journal of Manpower, 33(4), 367-382.

Mhlanga, O. (2020). The innovation-employment nexus: an analysis of the impact of Airbnb on hotel employment. Journal of Hospitality and Tourism Technology, 11(3), 407-423. https://doi.org/10.1108/JHTT-092019-0111 
Moin, M. F., Omar, M. K., Wei, F., Rasheed, M. I., \& Hameed, Z. (2021). Green HRM and psychological safety: How transformational leadership drives follower's job satisfaction. Current Issues in Tourism, 24(16), 2269-2277.

Mokhber, M., Khairuzzaman, W., \& Vakilbashi, A. (2018). Leadership and innovation: The moderator role of organization support for innovative behaviors. Journal of Management \& Organization, 24(1), 108-128.

Mumford, M. D., \& Licuanan, B. (2004). Leading for innovation: Conclusions, issues, and directions. The leadership quarterly, 15(1), 163-171.

Muñoz-Pascual, L., \& Galende, J. (2020). Ambidextrous relationships and social capability as employee well-being: The secret sauce for research and development and sustainable innovation performance. International Journal of Environmental Research and Public Health, 17(9), 3072.

Nielsen, M. B., Skogstad, A., Matthiesen, S. B., \& Einarsen, S. (2016). The importance of a multidimensional and temporal design in research on leadership and workplace safety. The Leadership Quarterly, 27(1), 142-155. Odoardi, C., Battistelli, A., Montani, F., \& Peiró, J. M. (2019). Affective commitment, participative leadership, and employee innovation: A multilevel investigation. Journal of Work and Organizational Psychology, 35(2), 103-113.

Parameswaran, R., \& Yaprak, A. (1987). A cross-national comparison of consumer research measures. Journal of International Business Studies, 18(1), 35-49.

Podsakoff, P. M., MacKenzie, S. B., Lee, J. Y., \& Podsakoff, N. P. (2003). Common method biases in behavioral research: a critical review of the literature and recommended remedies. Journal of Applied Psychology, 88(5), 879-903. $\quad$ https://doi.org/10.1037/00219010.88.5.879.

Rahimizhian, S., \& Irani, F. (2020). Contactless hospitality in a postCovid-19 world. International Hospitality Review. https://doi.org/10.1108/IHR-08-2020-0041

Rahimizhian, S., Avci, T., \& Eluwole, K. K. (2020). A conceptual model development of the impact of higher education service quality in guaranteeing edu-tourists' satisfaction and behavioral intentions. Journal of Public Affairs, 20(3), e2085. https://doi.org/10.1002/pa.2085

Rahimizhian, S., Ozturen, A., \& Ilkan, M. (2020). Emerging realm of 360degree technology to promote tourism destination. Technology in Society, 63, 101411. https://doi.org/10.1016/j.techsoc.2020.101411

Rank, J., Carsten, J. M., Unger, J. M., \& Spector, P. E. (2007). Proactive customer service performance: Relationships with individual, task, and leadership variables. Human Performance, 20(4), 363-390.

Ringle, C. M., Wende, S., \& Becker, J. M. (2015). SmartPLS 3. SmartPLS $\mathrm{GmbH}$.

Saether, E. A. (2019). Motivational antecedents to high-tech R\&D employees' innovative work behavior: Self-determined motivation, person-organization fit, organization support of creativity, and pay justice. The Journal of High Technology Management Research, 30(2), 100350.

Sagnak, M. (2012). The empowering leadership and teachers innovative behavior: The mediating role of innovation climate. African Journal of Business Management, 6(4), 1635-1641.

Schaufeli, W. B., Bakker, A. B., \& Salanova, M. (2006). The measurement of work engagement with a short questionnaire: A cross-national study. Educational and Psychological Measurement, 66(4), 701-716.

Schmitt, A., Den Hartog, D. N., \& Belschak, F. D. (2016). Transformational leadership and proactive work behavior: A moderated mediation model including work engagement and job strain. Journal of Occupational and Organizational Psychology, 89(3), 588-610.

Schumpeter, J. A. (1934). The theory of economic development: An inquiry into profits, capital, credit, interest, and the business cycle. Harvard University Press.
Segarra-Ciprés, M., Roca-Puig, V., \& Bou-Llusar, J. C. (2014). External knowledge acquisition and innovation output: an analysis of the moderating effect of internal knowledge transfer. Knowledge Management Research \& Practice, 12(2), 203-214.

Seibert, S. E., Kraimer, M. L., \& Liden, R. C. (2001). A social capital theory of career success. Academy of Management Journal, 44(2), 219-237.

Sousa, F. C., Nunes, F., \& Monteiro, I. (2019). Managers' attitudes to creativity and innovation practices in the creative industries. Tourism \& Management Studies, 15(1SI), 33-41. https://doi.org/10.18089/tms.2019.15SI04

Tierney, P., Farmer, S. M., \& Graen, G. B. (1999). An examination of leadership and employee creativity: The relevance of traits and relationships. Personnel Psychology, 52(3), 591-620.

Tu, Y., Lu, X., Choi, J. N., \& Guo, W. (2019). Ethical leadership and teamlevel creativity: Mediation of psychological safety climate and moderation of supervisor support for creativity. Journal of Business Ethics, 159(2), 551-565.

Tuan, L. T. (2021). Disentangling green service innovative behavior among hospitality employees: The role of customer green involvement. International Journal of Hospitality Management, 99, 103045.

UNWTO. (2020). UNWTO world tourism barometer. Available at https://www.e-unwto.org/loi/wtobarometereng

Wang, C. J., \& Yang, I. (2021). Why and How Does Empowering Leadership Promote Proactive Work Behavior? An Examination with a Serial Mediation Model among Hotel Employees. International Journal of Environmental Research and Public Health, 18(5), 2386.

Wu, C. H., \& Parker, S. K. (2017). The role of leader support in facilitating proactive work behavior: A perspective from attachment theory. Journal of Management, 43(4), 1025-1049.

Xu, Z., Yang, F., \& Peng, J. (2021). How does authentic leadership influence employee voice? From the perspective of the theory of $\begin{array}{lll}\text { planned behavior. Current 1-19. } & \text { Psychology, }\end{array}$ https://doi.org/10.1007/s12144-021-01464-6

Yamak, O. U., \& Eyupoglu, S. Z. (2021). Authentic leadership and service innovative behavior: mediating role of proactive personality. SAGE Open, 11(1), 2158244021989629 https://doi.org/10.1177/2158244021989629

Yilmaz, O., Yildirim, A., \& Yucedag, D. (2018). Assessment of personality from a new perspective: Characterix personality types inventory. International Journal of Scientific Research and Management, 6(03)

https://doi.org/10.18535/ijsrm/v6i3.el02

Yuan, F., \& Woodman, R. W. (2010). Innovative behavior in the workplace: The role of performance and image outcome expectations. Academy of Management Journal, 53(2), 323-342.

Zhang, W., Xu, F., \& Wang, X. (2020). How green transformational leadership affects green creativity: Creative process engagement as intermediary bond and green innovation strategy as boundary spanner. Sustainability, 12(9), https://doi.org/10.3390/su12093841

3841

Zhang, Y., Zhang, J., Forest, J., \& Chen, C. (2018). The negative and positive aspects of employees' innovative behavior: role of goals of employees and supervisors. Frontiers in psychology, 9, 1871. https://doi.org/10.3389/fpsyg.2018.01871

Zohar, D. (1980). Safety climate in industrial organizations: theoretical and applied implications. Journal of Applied Psychology, 65(1), 96-102. https://doi.org/10.1037/0021-9010.65.1.96 